\title{
TRIGO DURO: TOLERÂNCIA À TOXICIDADE DE ALUMÍNIO, MANGANÊS E FERRO EM SOLUÇÕES NUTRITIVAS $\left(^{1}\right.$ )
}

\author{
CARLOS EDUARDO DE OLIVEIRA CAMARGO $\left({ }^{2.3}\right)$, JOÃO CARLOS FELÍCIO $\left({ }^{2}\right)$, \\ JOSÉ GUILHERME DE FREITAS $\left({ }^{2,3}\right)$ \\ e ANTONIO WILSON PENTEADO FERREIRA FILHO ${ }^{2}$ )
}

\begin{abstract}
RESUMO
Avaliou-se o comportamento diferencial de 23 linhagens de trigo duro (Triticum durum L.) em comparação com os seguintes cultivares de trigo (T.aestivum L.): IAC-24, BH-1146, Siete Cerros e IAC-60, quanto aos níveis de $\mathrm{Al}^{3+}(0 ; 0,2 ; 0,4$; $0,6 ; 0,8$ e $1,0 \mathrm{mg} / \mathrm{L})$, de $\mathrm{Mn}^{2+}(0,11 ; 300 ; 600$ e $1.200 \mathrm{mg} / \mathrm{L})$ e de $\mathrm{Fe}^{2+}(0,56 ; 5$; 10 e $20 \mathrm{mg} / \mathrm{L}$ ) em solução nutritiva. Os cultivares de trigo Siete Cerros (sensível à toxicidade de $\mathrm{Al}^{3+}$ ), $\mathrm{BH}-1146, \mathrm{IAC}-60$ e IAC-24 (tolerantes à toxicidade de $\mathrm{Al}^{3+}$ ), exibiram crescimento das raízes na presença de $1 \mathrm{mg} / \mathrm{L}$ de $\mathrm{Al}^{3+}$, e todas as linhagens de trigo duro avaliadas foram totalmente sensíveis a $0,4 \mathrm{mg} / \mathrm{L} \mathrm{de} \mathrm{Al}^{3+}$, com paralisação irreversível do crescimento das raízes. O aumento das concentrações de $\mathrm{Mn}^{2+}(0,11$ a $1.200 \mathrm{mg} / \mathrm{L})$ e de $\mathrm{Fe}^{2+}(0,56$ a $20 \mathrm{mg} / \mathrm{L})$ nas soluçōes causou uma redução significativa no comprimento das raízes dos genótipos em estudo. As linhagens de trigo duro 1 (Avetoro "S" x Anhinga "S" - Purcell "S"/D.67.2), 2 (Cando - Yavaros "S"), 6 (Chen "S") e 8 (Carcomum "S") apresentaram-se muito tolerantes à toxicidade de $\mathrm{Mn}^{2+}$ em relação ao controle 'Siete Cerros'. O 'Siete Cerros' e as linhagens de trigo duro 1, 6, 12 (CI 14955 x Yavaros "S"- Gediz "S"/Tropic Bird), 16 e 21 (Swan "S") e 20 (Boyeros "S"/Cocorit-71/5/Crane/Ganso//Marte "S"/3/Tildillo "S"/4/ Memo "S") exibiram tolerância à presença de elevadas quantidades de $\mathrm{Fe}^{2+}$ nas soluções nutritivas.
\end{abstract}

Termos de indexação: trigo duro, Triticum durum L.; trigo, Triticum aestivum L., linhagens, cultivares, comprimento da raiz, toxicidade de alumínio, manganês c ferro, tolerância, sensibilidade.

( ${ }^{1}$ ) Com verba suplementar do Acordo do Trigo entre as Cooperativas de Produtores Rurais do Vale do Paranapanema e a Secretaria de Agricultura e Abastecimento do Estado de São Paulo, através do Instituto Agronômico. Recebido para publicação em 13 de julho de 1994 e aceito em 9 de agosto de 1995.

(2) Seção de Arroz e Cereais de Inverno, Instituto Agronômico (IAC), Caixa Postal 28, 13001-970 Campinas (SP).

(3) Com bolsa de pesquisa do CNPq. 


\title{
ABSTRACT \\ DURUM WHEAT: TOLERANCE TO ALUMINUM, MANGANESE AND IRON TOXICITIES IN NUTRIENT SOLUTIONS
}

\begin{abstract}
Twenty three durum wheat inbred lines were evaluated with four bread wheat cultivars (IAC-24, BH-1146, Siete Cerros and IAC-60) in three experiments, using nutrient solutions. In the first experiment, the following levels of $\mathrm{Al}^{3+}$ were used: $0 ; 0.2 ; 0.4 ; 0.6 ; 0.8$ and $1.0 \mathrm{mg} / \mathrm{L}$; in the second experiment, the following levels of $\mathrm{Mn}^{2+}$ were used: $0.11 ; 300 ; 600$ and $1.200 \mathrm{mg} / \mathrm{L}$; and in the third experiment, $\mathrm{Fe}^{2+}$ was used at: $0.56 ; 5 ; 10$ and $1.200 \mathrm{mg} / \mathrm{L}$. The wheat cultivars Siete Cerros (sensitive to $\mathrm{Al}^{3+}$ toxicity) and $\mathrm{BH}-1146$, IAC-24 and IAC-60 (tolerant to $\mathrm{Al}^{3+}$ toxicity) exhibited root growth in the presence of $1 \mathrm{mg} / \mathrm{L}$ of $\mathrm{Al}^{3+}$, and all evaluated durum wheat inbred lines were sensitive to $0.4 \mathrm{mg} / \mathrm{L}$ of $\mathrm{Al}^{3+}$, showing an irreversible root growth. As the $\mathrm{Mn}^{2+}$ and $\mathrm{Fe}^{2+}$ concentrations were increasead into the solutions, the root length of all studied genotypes presented a significant reduction. The durum wheat inbred lines 1 (Avetoro "S" x Anhinga "S" - Purcell "S"/ D.67.2), 2 (Cando - Yavaros "S"), 6 (Chen "S") e 8 (Carcomum "S") showed high level of tolerance to manganese toxicity in relation to 'Sicte Cerros' and the durum wheat inbred lines 1, 6, 12 (C) $14955 \times$ Yavaros "S"-Gediz"S"/Tropic Bird), 16 and 21 (Swan "S") and 20 (Boyeros "S"/Cocorit-71/5/Crane/Ganso//Marte"S"/3/Tildillo"S"/4/Memo "S") exhibited tolerance to the presence of high levels of $\mathrm{Fe}^{2+}$ into the nutrient solutions.
\end{abstract}

Index terms: durum wheat, Triticum durum L.; bread wheat, T. aestivum L., inbred lines, cultivars, root lenght, aluminum, manganese and iron toxicities, tolerance, sensitivity.

\section{INTRODUÇÃO}

A prática da calagem em solos ácidos e o cmprego de cultivares tolerantes à toxicidade de alumínio têm sido as principais causas para o sucesso da triticultura nas regiões de cerrado no Brasil ( $\mathrm{Ba}^{-}$ taglia et al., 1985, e Camargo, 1993).

Alguns solos não produzem efeitos tóxicos de $\mathrm{Mn}^{2+}$ em plantas sensíveis, mesmo em $\mathrm{pH} 5,0$ ou inferior, porque suas rochas-mães contêm baixo teor de $\mathrm{Mn}^{2+}$ em sua constituição (Foy, 1976). Grande parte da cultura do trigo no Estado de São Paulo está localizada em área de solos originários de basalto, rocha com elevados teores de $\mathrm{Mn}^{2+}$, sendo de grande interesse que os cultivares mostrem tolerância a esse elemento. Verificou-se que os mecanismos genéticos que conferem tolerância à toxicidade de alumínio e manganês em trigo são independentes (Foy et al., 1973, Camargo, 1983, Camargo et al., 1991). Empregando soluções nutritivas, classificaram-se 26 cultivares de trigo como sensíveis, moderadamente tolerantes $\mathrm{c}$ tolerantes à toxicidade de manganês (Camargo \& Ferreira Filho, 1992).

Nos últimos anos, a toxicidade de ferro vem constituindo sério problema para a cultura do trigo no Estado de São Paulo, seja cm condições de sequeiro, seja de irrigação por aspersão, provocando amarelecimento acentuado nas folhas inferiores das plantas. Esses sintomas ficam evidenciados nos anos chuvosos, quando em cultura de scqueiro, sendo mais freqüentes $\mathrm{cm}$ condições de irrigação, em decorrência do aparecimento de uma camada de adensamento no solo na profundidade de $20-30 \mathrm{~cm}$. Identificaram-se cultivares tolerantes e sensiveis à toxicidade de ferro, empregando-se soluções nutritivas (Camargo et al., 1988).

Selecionaram-se linhagens de trigo tolerantes, ao mesmo tempo, à toxicidade de $\mathrm{Al}^{3+}, \mathrm{Mn}^{2+} \mathrm{e}$ $\mathrm{Fe}^{2+}$, a partir do cruzamento entre o cultivar $\mathrm{BH}$ -1146, tolerante à toxicidade de $\mathrm{Al}^{3+}$ e sensível 
à toxicidade de $\mathrm{Fe}^{2+}$ e $\mathrm{Mn}^{2+}$, e o 'Siete Cerros', sensível à toxicidade de $\mathrm{Al}^{3+}$, porém tolerante à

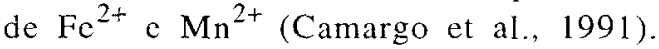

O trigo cultivado no Brasil é de primavera, pertence à espécie Triticum aestivum L. e apresenta no cromossomo 1 do genoma $D$ genes importantes relacionados às características da farinha (força do glúten), de grande importância na indústria de panificação (Welsh \& Hehn, 1964) e no cromossomo 4 do genoma $\mathrm{D}$, um gene dominante que condiciona tolerância à toxicidade de $\mathrm{Al}^{3+}$ (Lagos et al., 1991).

Embora o trigo duro (T.durum L.) não tenha qualidades tecnológicas para panificação, possui semolina com alto teor de proteína, sendo, pois, preferido para elaboração de macarrão que se torna duro, translúcido e firme após o cozimento (Martin et al., 1976, Camargo, 1993). Linhagens de trigo duro avaliadas em soluções nutritivas $\mathrm{e} \mathrm{cm}$ solo ácido mostraram-se muito sensíveis à toxicidade de $\mathrm{Al}^{3+}$ (Camargo et al., 1992).

Considerando a implantação da cultura do trigo duro em condições de irrigação no Estado de São Paulo, o presente trabalho tem por objetivo avaliar 23 linhagens promissoras de trigo duro, em comparação com quatro cultivares de trigo comum, quanto à tolerância à toxicidade de $\mathrm{Al}^{3+}, \mathrm{Mn}^{2+}$ e $\mathrm{Fe}^{2+}$, empregando soluções nutritivas.

\section{MATERIAL E MÉTODOS}

\subsection{Origem dos genótipos estudados}

As 23 linhagens de trigo duro e respectivas origens foram as seguintes:
Linhagens
Cruzamentos

Avetoro "S" x Anhinga "S" - Purcell "S"/D.67.2

6 e 23 Chen "S" = Shearwater - Yavaros "S"
Carcomum "S"

Siskin - Crane x Shearwater "S"

Dackiye "S"- Rabicorno "S" x Rokel "S"

Stifftail "S"- Yavaros "S"

CI 14955 x Yavaros "S" - Gediz "S"/ Tropic Bird

Gediz "S" - Bartmeise "S"/ Ege x Ruff "S"

Gediz "S" - Cocorit-71

Yavaros - 79 "S"

16 e 21 Swan "S" = Gediz "S"-Flamingo "S"/Teal "S"

Boyeros "S" - Yavaros "S"

Gediz "S" - Yavaros "S"

61150/Leeds//Gallo "S"/3/Garza "S"/4 /Mexicali "S"/5/S 15

Boycros "S"/Cocorit-71/5/Crane "S"/ Ganso "S"// Marte "S"/3/Tildillo "S"/4/ Memo "S"

Sacaba -81

As origens dos cultivares de trigo utilizados como controles foram as seguintes:

24 IAC-24 - Tolerante à toxicidade de alumínio e sensível à de ferro, originário de seleções realizadas no Instituto Agronômico, Campinas, a partir do híbrido IAS-51 x IRN 597-70.

25 IAC-60 - Tolerante à toxicidade de alumínio e sensível à de ferro, provindo de seleções feitas no Instituto Agronômico, a partir do híbrido IRN 33-70 x IAC-5.

26 BH-1146 - Tolerante à toxicidade de alumínio e sensível à de ferro e manganês, proveniente de seleção realizada no Instituto Agronômico de Belo Horizonte (MG), oriundo de cruzamento 'Ponta Grossa I' $x$ 'Fronteira', híbrido esse que foi cruzado com o 'Mentana'. 
27 Siete Cerros - Sensível à toxicidade de alumínio e tolerante à de manganês e ferro, introduzido do CIMMYT, procedente do cruzamento: 'Penjamo 62 '/'Gabo 55'.

\subsection{Avaliação dos genótipos tolerantes à toxicidade de $\mathrm{Al}^{3+}$}

As plântulas das linhagens de trigo duro e dos cultivares de trigo comum foram testadas em condições de laboratório, para tolerância a $0 ; 0,2 ; 0,4$; 0,$6 ; 0,8$ e $1,0 \mathrm{mg} / \mathrm{L}$ de $\mathrm{Al}^{3+}$ em soluções nutritivas preparadas em vasilhas plásticas de 8,3 litros de capacidade, conforme Moore et al. (1976) e Camargo \& Oliveira (1981). O delineamento estatístico empregado foi de blocos ao acaso com parcelas subdivididas, compostas por seis concentrações de alumínio e, as subparcelas, pelos genótipos. Efetuaram-se duas repetições para cada solução-tratamento. Determinou-se a quantidade de crescimento da raiz primária, medindo-se o comprimento em cada plântula no final das 120 horas, na solução completa, e subtraindo-se o comprimento da mesma raiz, medida no final do crescimento, na solução de tratamento (um décimo da concentração de nutrientes da solução completa). Avaliaram-se os dados, considerando-se a média de comprimento da raiz primária central das dez plântulas de cada genótipo, em 120 horas de crescimento nas soluções nutritivas completas sem alumínio, que se seguiu a 24 horas de crescimento nas soluções de tratamento contendo seis diferentes concentrações de alumínio.

\subsection{Avaliação dos genótipos tolerantes a manganês e ferro}

As plântulas das linhagens e dos cultivares foram testadas em condição de laboratório em dois experimentos: no primeiro, para tolerância a 0,$11 ; 300$; 600 e $1.200 \mathrm{mg} / \mathrm{L}$ de $\mathrm{Mn}^{2+}$ em soluções nutritivas, conforme método de Camargo (1988) e, no segundo, para tolerância a 0,$56 ; 5,0 ; 10,0$ e $20,0 \mathrm{mg} / \mathrm{L}$ de $\mathrm{Fe}^{2+}$ em soluções nutritivas, conforme Camargo et al. (1989). O delineamento estatístico utilizado nos dois ensaios foi de blocos ao acaso com parcelas subdivididas, compostas pelas quatro concentrações de manganês ou ferro, conforme o experimento e, as subparcelas, pelos genótipos. Efetuaram-se quatro repetições para cada um dos experimentos.

Os dados de crescimento das raízes foram obtidos, considerando-se a média do seu crescimento em dez plântulas de cada genótipo em cada repetição e experimento, após permanência por dozc dias nas diferentes soluções.

Fez-se análise da variância de cada experimento para verificar o efeito de concentrações de $\mathrm{Mn}^{2+}$ ou $\mathrm{Fe}^{2+}$, calculando-se os parâmetros das equações de regressão linear e os coeficientes de determinação para cada genótipo, considerando o comprimento médio das raízes em função da concentração de manganês $\mathfrak{c}$ ferro nas soluções nutritivas. Calcularam-se, também, os parâmetros das equações de segundo grau (quadráticas), considerando-se as respostas do comprimento das raízes dos cultivares BH-1146 e Siete Cerros, em função das quatro concentrações de ferro.

\section{RESULTADOS E DISCUSSÃO}

O comprimento médio das raízes das 23 linhagens de trigo duro e dos quatro cultivares de trigo, medido após 120 horas de crescimento nas soluções nutritivas completas e depois de 24 horas de crescimento nas soluções de tratamento, contendo seis diferentes concentrações de alumínio $(0 ; 0,2 ; 0,4$; 0,$6 ; 0,8$ c $1,0 \mathrm{mg} / \mathrm{L}$ ), cncontra-se no quadro 1 .

Considerando as médias dos diferentes genótipos estudados em soluções de tratamento isentas de $\mathrm{Al}^{3+}$, verifica-se que o ' $\mathrm{BH}-1146$ ' mostrou as raízes mais compridas em relação aos demais. Essas observações confirmam resultados de Camargo et al.(1987): em uma solução com níveis adequados de nutriente, na ausência de alumínio, com pH 4,0, o 'BH-1146' apresentou o seu potencial genético no crescimento rápido das raízes, condição essa específica de cada genótipo.

Nas soluções de tratamento contendo $\mathrm{Al}^{3+}$, todos os cultivares reduziram o crescimento radicular $\mathrm{em}$ relação ao das soluçōes de tratamento contendo 0 $\mathrm{mg} / \mathrm{L}$ de $\mathrm{Al}^{3+}$. As linhagens de trigo duro 3, 8, $10,11,13,17$ e 20 revelaram-se sensíveis ao $\mathrm{Al}^{3+}$, 
Quadro 1. Comprimento médio das raízes dos genótipos de trigo, Triticum aestivum L., e de trigo duro, Triticum durum L., medido após 120 horas de crescimento na solução nutritiva completa, que se seguiu a 24 horas de crescimento nas soluções de tratamento contendo seis concentrações de $\mathrm{Al}^{3+}$

Linhagens

Concentraçōes de alumínio nas soluçōes ( $\mathrm{mg} / \mathrm{L}$ )

e Cultivares

$0 \quad 0$,

0,4

0,6

0,8

1,0

$\mathrm{mm}$

T. durum L.

\begin{tabular}{|c|c|c|c|c|c|c|}
\hline 1 & 29,8 & 8,1 & 0,0 & 0,0 & 0,0 & 0.0 \\
\hline 2 & 30,4 & 2,2 & 0,0 & 0,0 & 0,0 & 0,0 \\
\hline 3 & 37,0 & 0,0 & 0,0 & 0,0 & 0,0 & 0,0 \\
\hline 4 & 57,0 & 7,8 & 0,0 & 0,0 & 0,0 & 0,0 \\
\hline 5 & 25,8 & 0,6 & 0,0 & 0.0 & 0,0 & 0.0 \\
\hline 6 & 48,2 & 9,2 & 0,0 & 0,0 & 0,0 & 0.0 \\
\hline 7 & 49,0 & 10,6 & 0,0 & 0,0 & 0,0 & 0,0 \\
\hline 8 & 46,1 & 0,0 & 0,0 & 0,0 & 0,0 & 0,0 \\
\hline 9 & 33,5 & 9,6 & 0,0 & 0,0 & 0,0 & 0,0 \\
\hline 10 & 48,3 & 0,0 & 0,0 & 0,0 & 0,0 & 0,0 \\
\hline 11 & 48,0 & 0,0 & 0,0 & 0,0 & 0,0 & 0,0 \\
\hline 12 & 40,6 & 23,1 & 0,0 & 0,0 & 0,0 & 0,0 \\
\hline 13 & 28,9 & 0,0 & 0,0 & 0,0 & 0,0 & 0,0 \\
\hline 14 & 52,4 & 7,3 & 0,0 & 0,0 & 0,0 & 0,0 \\
\hline 15 & 41,4 & 2,9 & 0,0 & 0,0 & 0,0 & 0,0 \\
\hline 16 & 45,1 & 6,2 & 0.0 & 0,0 & 0,0 & 0,0 \\
\hline 17 & 53,7 & 0,0 & 0,0 & 0,0 & 0,0 & 0,0 \\
\hline 18 & 62,4 & 12,2 & 0,0 & 0,0 & 0,0 & 0,0 \\
\hline 19 & 46,8 & 10,0 & 0,0 & 0,0 & 0,0 & 0,0 \\
\hline 20 & 45,4 & 0,0 & 0,0 & 0,0 & 0,0 & 0,0 \\
\hline 21 & 48,5 & 1,5 & 0,0 & 0,0 & 0,0 & 0,0 \\
\hline 22 & 54,4 & 23,7 & 0,0 & 0,0 & 0,0 & 0,0 \\
\hline 23 & 35,7 & 3,1 & 0,0 & 0,0 & 0,0 & 0,0 \\
\hline \multicolumn{7}{|c|}{ aestivum $\mathrm{L}$. } \\
\hline $\mathrm{AC}-24$ & 36,8 & 10,8 & 21,3 & 36,6 & 38,2 & 33,9 \\
\hline AC -60 & 60,5 & 55,6 & 55,0 & 58,9 & 67,1 & 60.3 \\
\hline H-1146 & 80,3 & 46,7 & 62,1 & 72,9 & 85,5 & 79,8 \\
\hline te Cerros & 66,9 & 32,7 & 42,9 & 39,4 & 31,9 & 5,1 \\
\hline
\end{tabular}




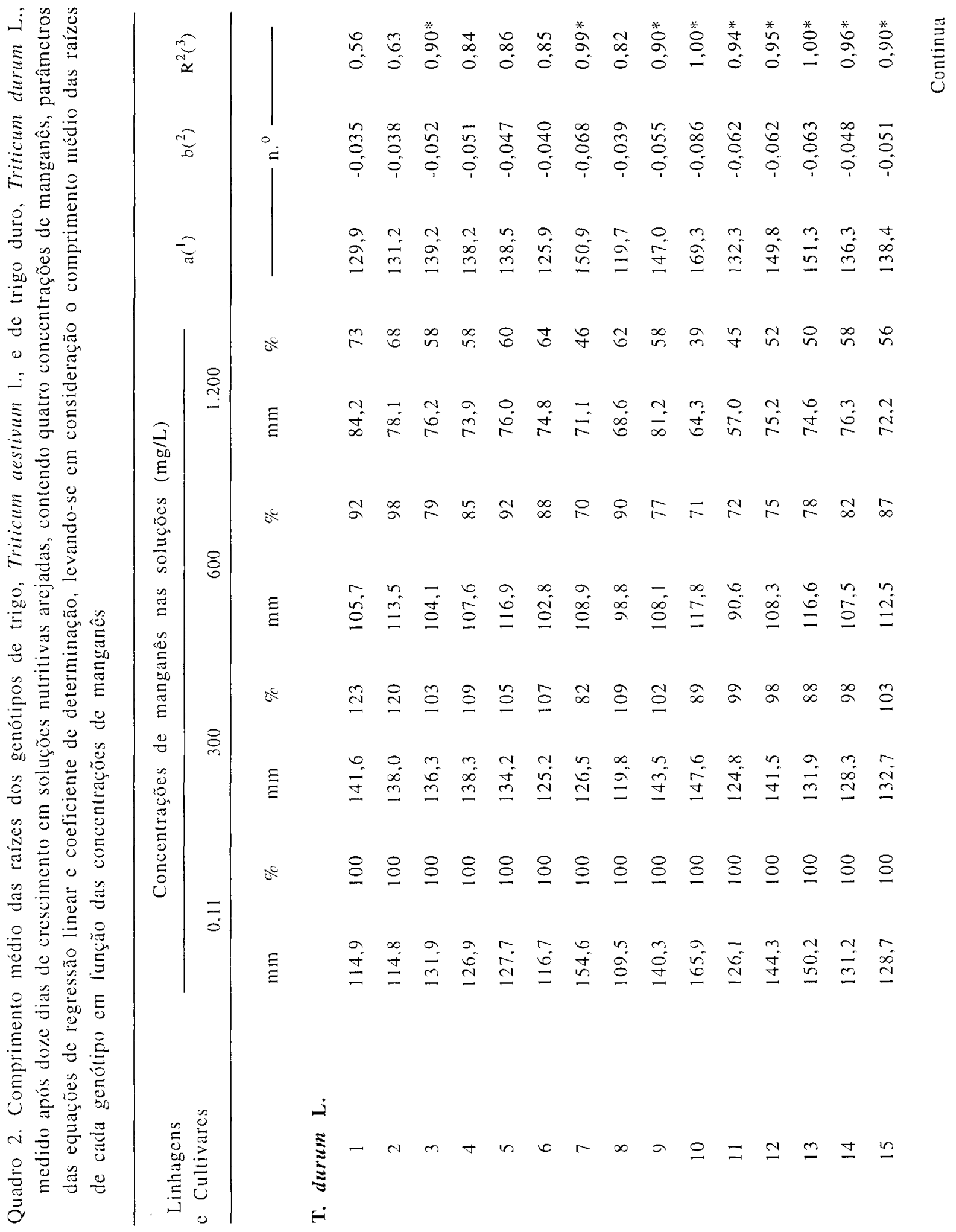




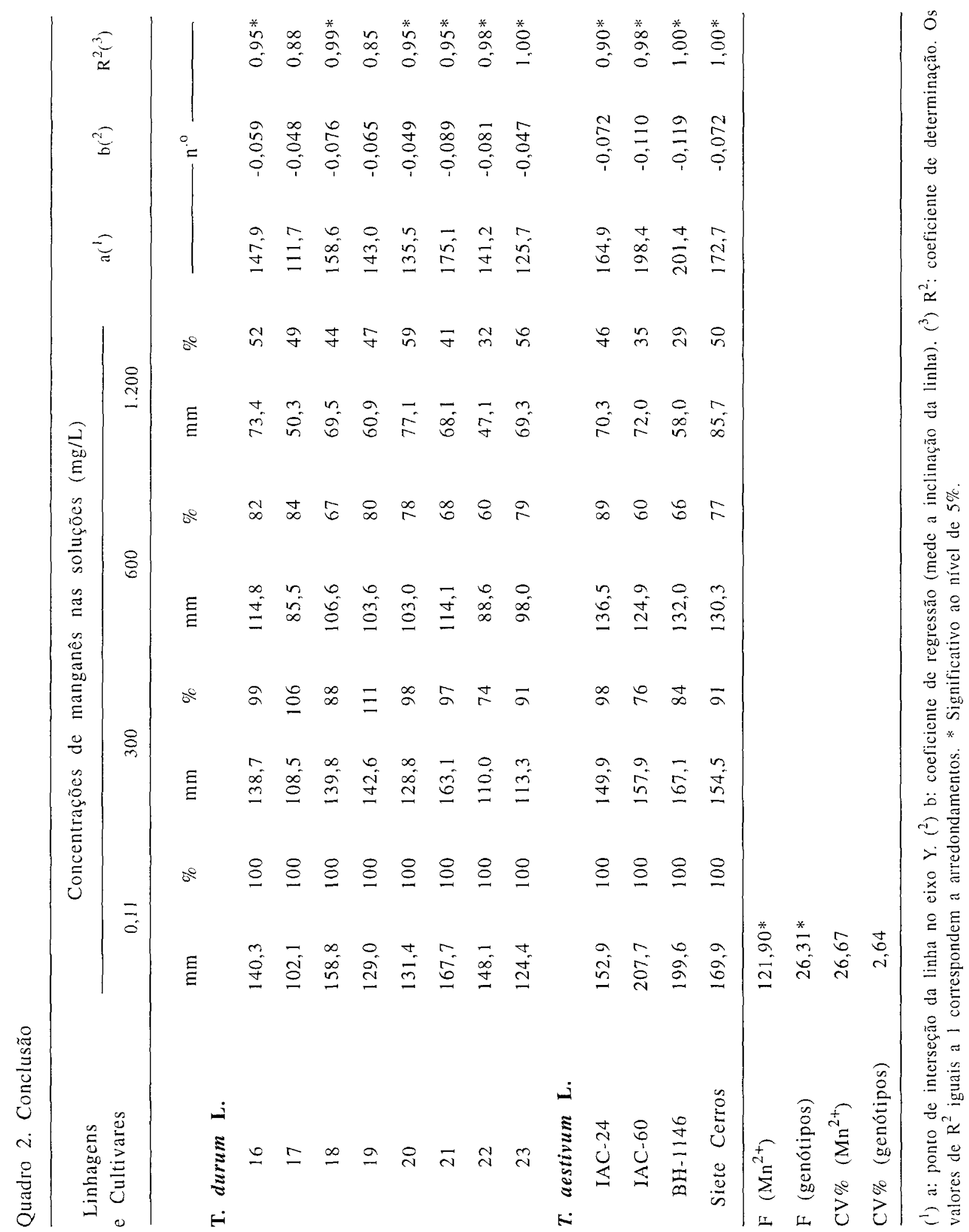


uma vez que suas raízes primárias deixaram de crescer em solução de alumínio, após 24 horas em solução de tratamento contendo $0,2 \mathrm{mg} / \mathrm{L}$ de $\mathrm{Al}^{3+}$. As demais linhagens de trigo duro $\mathrm{c}$ os cultivares de trigo comum exibiram crescimento das raízes primárias e foram considerados tolerantes a essa concentração de $\mathrm{Al}^{3+}$.

Todas as linhagens de trigo duro foram totalmente sensíveis a $0,4 \mathrm{mg} / \mathrm{L}$ de $\mathrm{Al}^{3+}$, isto é, apresentaram paralisação irreversível no crescimento das raízes após permanecer 24 horas nas soluções desse tratamento.

Os cultivares de trigo comum mostraram-se tolerantes em todas as concentrações de $\mathrm{Al}^{3+}(0,2$ a $1,0 \mathrm{mg} / \mathrm{L})$.

A grande sensibilidade à toxicidade de $\mathrm{Al}^{3+}$, demonstrada pelas linhagens de trigo duro em relação aos cultivares de trigo, confirma os resultados de Camargo et al. (1992), nos quais linhagens dessa espécie também se mostraram altamente sensíveis às condições de solo ácido e à presença de $1 \mathrm{mg} / \mathrm{L}$ de $\mathrm{Al}^{3+}$ em soluções nutritivas.

Dezesseis das linhagens de trigo duro estudadas apresentaram crescimento radicular após o tratamento $\mathrm{em}$ soluções contendo $0,2 \mathrm{mg} / \mathrm{L}$ de $\mathrm{Al}^{3+}$, revelando, porém, alta sensibilidade à presença de $1 \mathrm{mg} / \mathrm{L}$ de $\mathrm{Al}^{3+}$ nas soluções. A pequena tolerância apresentada por essas linhagens ainda seria insuficiente para permitir seu cultivo em solos ácidos, levando em consideração resultados de trabalhos anteriores, onde cultivares de trigo comum c linhagens de trigo duro, sensíveis a $1 \mathrm{mg} / \mathrm{L}$ de $\mathrm{Al}^{3+}$ $\mathrm{cm}$ soluções nutritivas, apresentaram baixa produtividade em solos ácidos (Camargo et al., 1992).

Seria de grande importância incorporar nas linhagens de trigo duro, pelo método do retrocruzamento, o fator genético de tolerância ao alumínio presente nos cultivares de trigo comum. Desse modo, seria possível cultivar essa espécie sem restrição em solos ácidos, uma vez que várias linhagens têm exibido alto potencial produtivo $\mathrm{cm}$ solos corrigidos (Camargo et al., 1992, 1993).

A análise da variância para crescimento das raízes dos 27 genótipos em um experimento contendo quatro concentrações de $\mathrm{Mn}^{2+}$ mostrou, pelo teste $\mathrm{F}$, efeitos significativos ao nível de $5 \%$, de repetições, concentrações de manganês, genótipos e interação genótipos x concentrações de manganês (Quadro 2).

O quadro 2 apresenta o comprimento médio das raízes dos 27 genótipos medidos após doze dias de crescimento em soluções contendo quatro diferentes concentrações de manganês.

Todos os genótipos mostraram redução no crescimento radicular à medida que as concentrações de $\mathrm{Mn}^{2+}$ nas soluções aumentaram de 0,11 para $1.200 \mathrm{mg} / \mathrm{L}$.

Os resultados confirmaram ser o ' $\mathrm{BH}-1146$ ' muito sensível à toxicidade de $\mathrm{Mn}^{2+}$ (Camargo \& Ferreira Filho, 1992). No ensaio considerado, houve redução de $71 \%$ no crescimento das suas raízes à medida que as concentrações de $\mathrm{Mn}^{2+}$ aumentavam de 0,11 para $1.200 \mathrm{mg} / \mathrm{L}$. Também demonstraram alta sensibilidade o cultivar de trigo IAC $-60 \mathrm{c}$ as linhagens de trigo duro 10, 21 e 22, que exibiram redução do sistema radicular, de 59 a $68 \%$, à medida que se elevaram as concentraçōes de $\mathrm{Mn}^{2+}$ de 0,11 para $1.200 \mathrm{mg} / \mathrm{L}$.

Por outro lado, as linhagens de trigo duro 1 , 2,6 e 8 apresentaram-se muito tolerantes em relação ao 'Siete Cerros', utilizado como controle, com reduções de 27 a $38 \%$ no comprimento das raízes, nas mesmas condições.

Os parâmetros das equações de regressão linear e os coeficientes de determinação, considerando-se o comprimento médio das raízes de cada genótipo, em função das quatro concentrações de manganês, encontram-se no quadro 2.

Verifica-se que os coeficientes de regressão (b) para 'Siete Cerros' (tolerante à toxicidade de $\mathrm{Mn}^{2+}$ ) foi de $-0,072$, e para 'BH-1146' (sensível à toxicidade de $\mathrm{Mn}^{2+}$ ) foi de $-0,119$. O 'IAC-60' e as linhagens de trigo duro 10,21 e 22 apresentaram coeficiente de regressão variando de $-0,081$ a $-0,110$, confirmando o elevado grau de sensibilidade exibido por esses genótipos. 
Por outro lado, as linhagens de trigo duro 1 , 2, 6 e 8 apresentaram coeficientes de regressão variando de $-0,035$ a $-0,040$, que, em comparação com o coeficiente mostrado pelos cultivares $\mathrm{BH}-1146$ $(-0,119)$ e Siete Cerros $(-0,072)$, evidencia o elevado grau de tolerância apresentado por esses genótipos.

$\mathrm{Na}$ figura 1, encontram-se as equações de regressão linear dos cultivares BH-1146 e Siete Cerros. Os resultados mostraram, para o ' $\mathrm{BH}-1146$ ', maior inclinação da linha em relação ao 'Siete Cerros', confirmando sua maior sensibilidade às concentrações de $\mathrm{Mn}^{2+}$.

Os coeficientes de determinação nas análises de correlação entre os comprimentos das raízes e as concentrações de $\mathrm{Mn}^{2+}$ mostram elevado grau de associação negativa entre essas variáveis (Quadro 2).

A análise da variância para crescimento das raízes dos 27 genótipos estudados no experimento contendo quatro concentrações de $\mathrm{Fe}^{2+}$ mostrou, pelo teste $\mathrm{F}$, efeitos significativos ao nível de $5 \%$, de

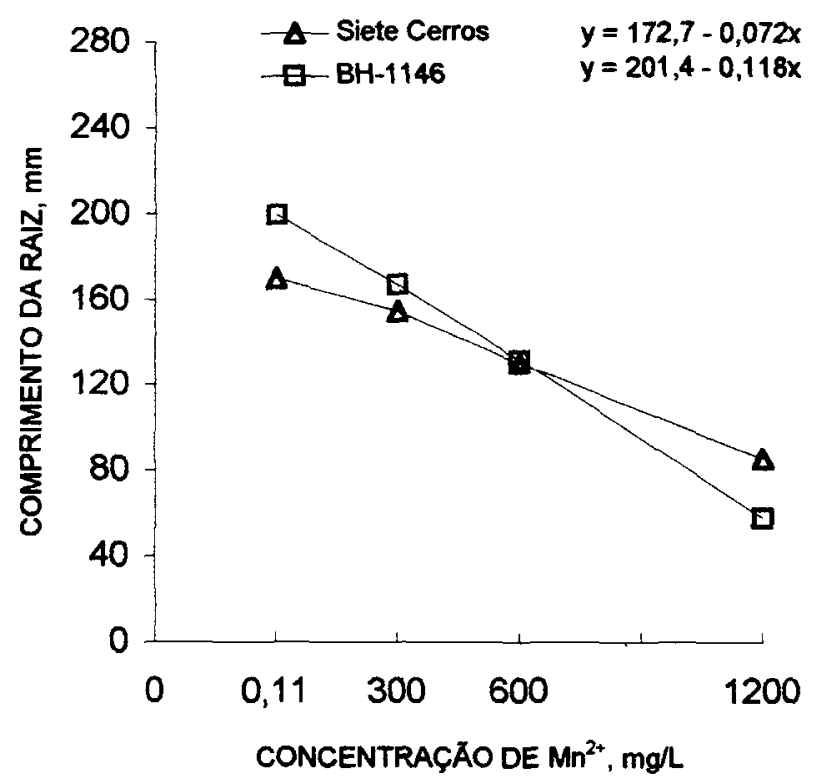

Figura 1. Respostas lineares do comprimento das raízes dos cultivares de trigo Siete Cerros e BH-1146, após doze dias de crescimento em soluções nutritivas arejadas contendo quatro concentrações de $\mathrm{Mn}^{2+}$. repetições, concentrações de $\mathrm{Fe}^{2+}$, genótipos e interação genótipos x concentrações de ferro (Quadro 3).

Os comprimentos médios das raízes dos 27 genótipos, medidos após doze dias de crescimento em soluções contendo quatro diferentes concentrações de ferro, encontram-se no quadro 3.

Considerando as médias dos diferentes genótipos em solução contendo $0,56 \mathrm{mg} / \mathrm{L}$ de ferro, verifica-se que o ' $\mathrm{BH}-1146$ ' mostrou as raízes mais compridas, confirmando o seu potencial genético no crescimento delas.

Estudando o comportamento de cada genótipo nas diferentes concentrações de ferro, verifica-se que, à medida que essas concentrações foram aumentadas, houve reduções no crescimento das raízes de todos os genótipos.

No ensaio considerado, o 'BH-1146' foi muito sensível à toxicidade de ferro, com redução de $88 \%$ no crescimento de suas raízes à medida que se aumentou a concentração de ferro de 0,56 para 10 $\mathrm{mg} / \mathrm{L}$. O cultivar Siete Cerros e as linhagens de trigo duro $1,6,12,16,20$ e 21 apresentaram-se como tolerantes, com reduções de 46 a $51 \%$ no comprimento das raízes nas mesmas condições. Os demais genótipos exibiram moderada tolerância à toxicidade de $\mathrm{Fe}^{2+}$.

Os parâmetros das equações de regressão linear e os coeficientes de determinação em função do comprimento médio das raízes de cada genótipo nas quatro concentrações de $\mathrm{Fe}^{2+}$, constam do quadro 3.

O coeficiente de regressão (b) para 'Siete Cerros' (tolerante à toxicidade de $\mathrm{Fe}^{2+}$ ) foi de $-4,690 \mathrm{e}$ para o 'BH-1146' (sensível à toxicidade de $\mathrm{Fe}^{2+}$ ), de $-7,043$. Os demais genótipos estudados mostraram coeficientes de regressão variando de $-3,065$ a $-5,386$, que, em comparação com o coeficiente apresentado pelo ' $\mathrm{BH}-1146$ ', evidencia maior grau de tolerância.

Apesar de os coeficientes de determinação entre o comprimento das raízes e as concentrações de ferro serem significativos somente para linhagens de trigo duro 1, 6 e 13 e para o 'Siete Cerros', 


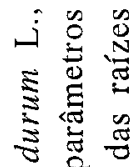

푼

气 $\stackrel{\Xi}{\Xi}$

충

苛兽

品 节

$\Xi$ 远

$\therefore 8$

-

广完恶

芌导

密焉

동

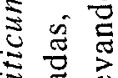

政

要

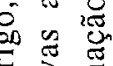

约

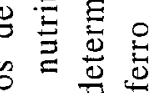

(n)

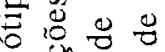

要

क क ज :

व

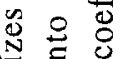

过 00

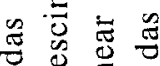

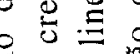

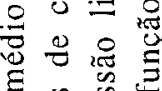

$\Xi$ g

웜 莺

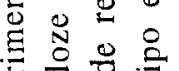

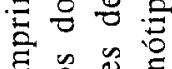

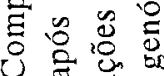

ri $\frac{\tilde{J}}{0} \frac{\pi}{\tilde{J}}$

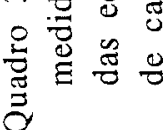

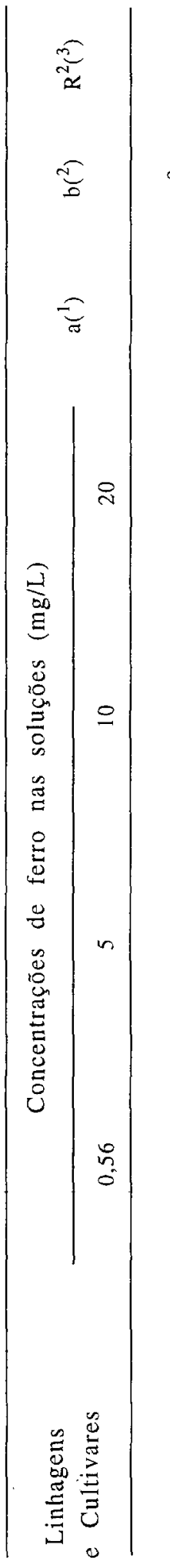

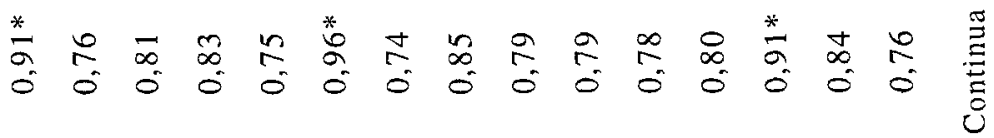

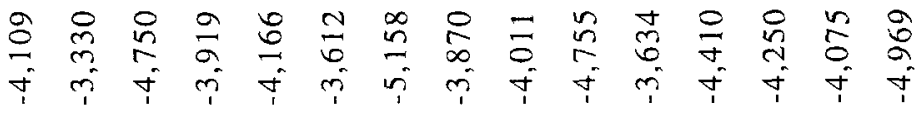

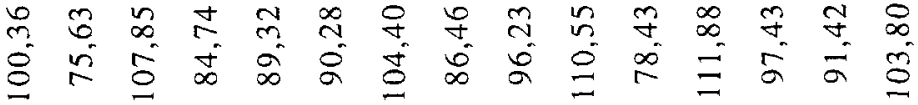

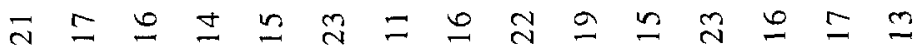

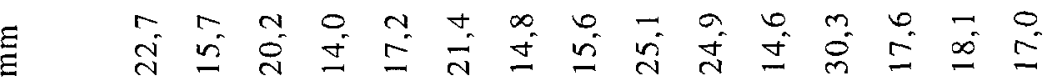

๙

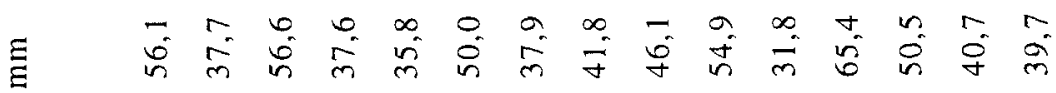

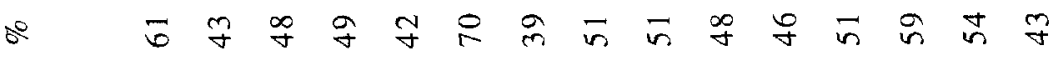

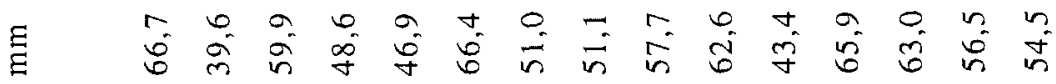

용ㅇㅇㅇㅇㅇㅛ

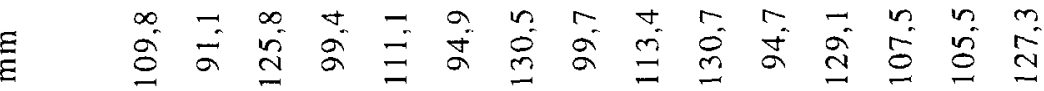

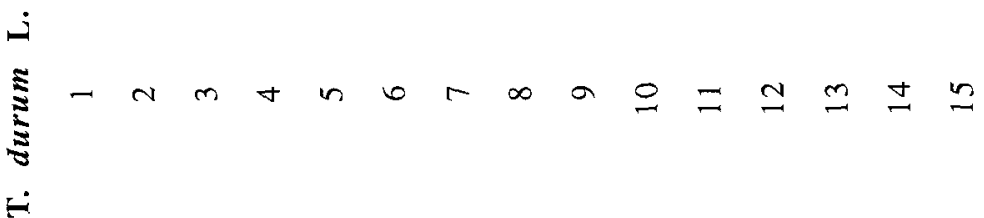




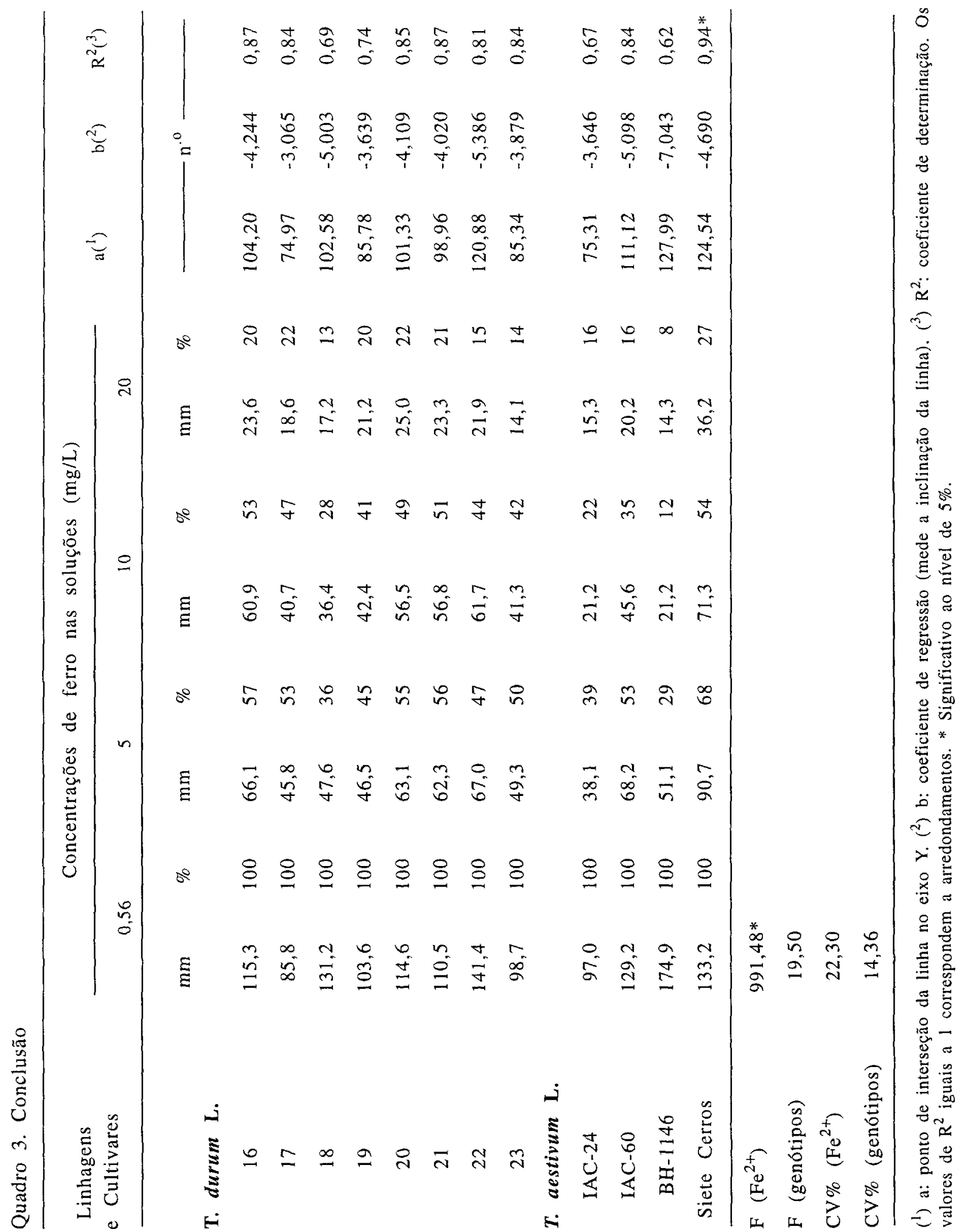


em razão do pequeno número de observações, os demais genótipos exibiram valores elevados, mostrando grande associação negativa entre as duas variáveis analisadas.

As equaçōes de segundo grau (quadráticas), considerando-se as respostas dos comprimentos das raízes dos cultivares BH-1146 e Siete Cerros, em função das quatro concentrações de ferro, representadas na figura 2, explicaram melhor os dados obtidos, apresentando cocficientes de determinação de 0,96 e 0,99 respectivamente. Para 'Siete Cerros', houve menor inclinação da curva, confirmando sua maior tolerância às concentrações crescentes de ferro nas soluções nutritivas.

Os resultados mostraram que as linhagens dc trigo duro 1 e 6 exibiram, ao mesmo tempo, elevada tolerância à toxicidade de ferro e manganês. Esses genótipos poderiam ser utilizados como fontes genéticas para essa tolerância em cruzamentos com os cultivares de trigo BH-1146, IAC-60 e IAC-24, tolerantes à toxicidade de alumínio, seguidos de retrocruzamentos para ambos os parentais, visando

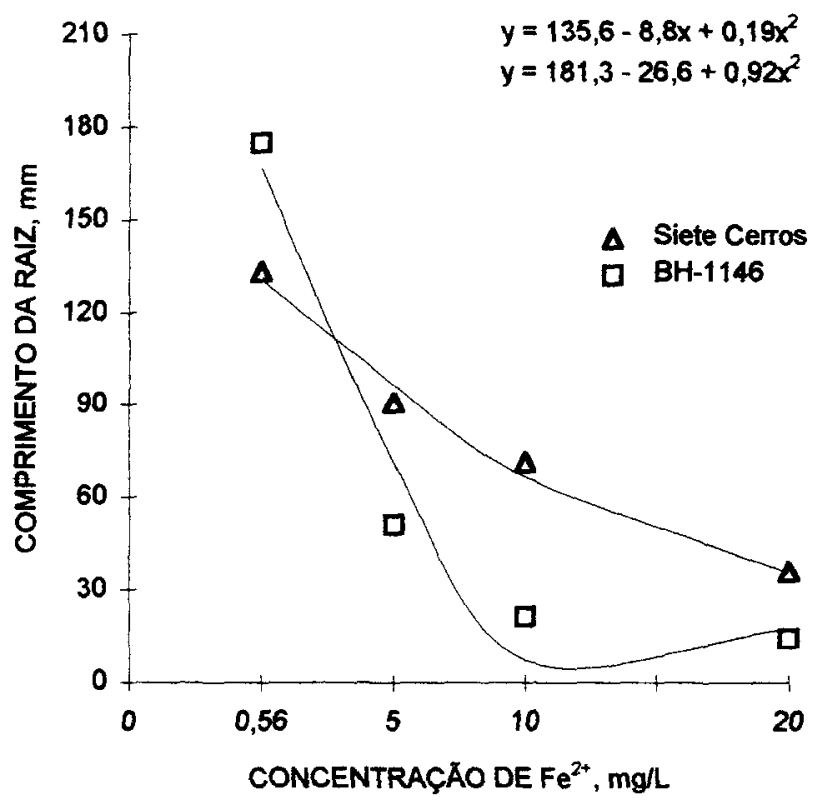

Figura 2. Curvas de resposta do comprimento das raízes dos cultivares de trigo Siete Cerros e $\mathrm{BH}-1146$, após doze dias de crescimento em soluções nutritivas arejadas contendo quatro concentraçōes de $\mathrm{Fe}^{2+}$. à obtenção de linhagens de trigo duro e de trigo comum, mostrando, simultaneamente, tolerância à toxicidade de $\mathrm{Al}^{3+}, \mathrm{Mn}^{2+}$ e $\mathrm{Fe}^{2+}$.

\section{CONCLUSÕES}

1. Todas as linhagens de trigo duro mostraram-se sensíveis à toxicidade de $\mathrm{Al}^{3+} \mathrm{em}$ relação aos cultivares de trigo comum utilizados como controle.

2. As linhagens de trigo duro 1 (Avetoro "S" $x$ Anhinga "S" - Purcell "S"/D.67.2) e 6 (Chen "S") apresentaram-se tolerantes à toxicidade de $\mathrm{Mn}^{2+}$ quanto à de $\mathrm{Fe}^{2+}$.

\section{REFERÊNCIAS BIBLIOGRÁFICAS}

BATAGLIA, O.C.; CAMARGO, C.E. de O.; OLIVEIRA, O.F.; NAGAI, V. \& RAMOS, V.J. Resposta a calagem de três cultivares de trigo com tolerância diferencial ao alumínio. Revista Brasileira de Ciência do Solo, Campinas, 9:139-147, 1985.

CAMARGO, C.E. de O. Melhoramento do Trigo. III. Evidência de controle genético na tolerância ao manganês e alumínio tóxico em trigo. Bragantia, Campinas, 42:91-103, 1983.

CAMARGO, C.E. de O. Tolerance of wheat cultivars and evidence of genetic control to different levels of manganese in nutrient solution. In: INTERNATIONAL SYMPOSIUM ON SOILS AND PLANTS: CONTRIBUTED PAPERS. Adelaide, 1988. Proceedings. Adelaide, Waite Agricultural Research Institute/University of Adelaide, 1988. p.109-112.

CAMARGO, C.E. de O. Trigo. In: FURLANI, M.A.C. \& VIÉGAS, G.P., eds. O melhoramento de plantas no Instituto Agronómico. Campinas, Instituto Agronômico, 1993. p.433-488.

CAMARGO, C.E de O.; CAMARGO, C.R. de O.; FELÍCIO, J.C.; FERREIRA FILHO, A.W.P.; SANTOS, R.R \& DECOT, G. Avaliação das caracteristicas agronomicas e tecnólogicas de genótipos de trigo duro, trigo e triticale. Campinas, Instituto Agronômico, 1993. 27p. (Boletim Científico, 29)

CAMARGO, C.E. de O.; FELÍCIO, J.C.; FREITAS, J.G. de \& FERREIRA FILHO, A.W.P. Tolerância de trigo, triticale e centeio a diferentes níveis de ferro em solução nutritiva. Bragantia, Campinas, 47(2):295304, 1988. 
CAMARGO, C.E. de O.; FELÍCIO, J.C. \& ROCHA JÚNIOR, L.S. Trigo: tolerância ao alumínio em solução nutritiva. Bragantia, Campinas, 46(2):183. $190,1987$.

CAMARGO, C.E. de O. \& FERREIRA FILHO, A.W.P. Tolerância de cultivares de trigo a diferentes níveis de manganês em solução nutritiva. Pesquisa Agropecuária Brasileira, Brasília, 27(3):417-422, 1992.

CAMARGO, C.E. de O.; FREITAS, J.G. de \& FERREIRA FILHO, A.W.P. Efeito de diferentes doses de Fe em solução nutritiva no desenvolvimento da raiz primária do trigo. Pesquisa Agropecuária Brasileira, Brasília, 24(12):1529-1535, 1989.

CAMARGO, C.E. de O. \& OLIVEIRA, O.F. de. Tolerância de cultivares de trigo a diferentes níveis de alumínio em solução nutritiva e no solo. Bragantia, Campinas, 40:21-31, 1981.

CAMARGO, C.E de O.; ROCHA JÚNIOR, L.S. \& FERREIRA FILHO, A.W.P. Melhoramento do trigo: XXVI. Avaliação de linhagens com tolerância à toxicidade de alumínio, manganês e ferro em soluções nutritivas. Bragantia, Campinas, 50(2):247-260, 1991.

CAMARGO, C.E. de O.; SANTOS, R.R. dos \& PETTINELLI JÚNIOR, A. Trigo duro: tolerância à toxicidade do alumínio em soluções nutritivas e no solo. Bragantia, Campinas, 51(1):69-76, 1992.
FOY, C.D. General principles involved in screening plants for aluminum and manganese tolerance. In: WORKSHOP ON PLANT ADAPTATION TO MINERAL STRESS IN PROBLEM SOILS. Beltsville, 1976. Proceedings. Ithaca, Cornell University, 1976. p.255-267.

FOY, C.D.; FLEMING, A.L. \& SCHWARTZ, J.W. Opposite aluminum and manganese tolerances of two wheat varieties. Agronomy Journal, Madison, 65(1): 123-126, 1973.

LAGOS, M.B.; FERNANDES, M.I.B de M.; CAMARGO, C.E.de O.; FEDERIZZI, L.C. \& CARVALHO, F.I.F. de. Genetics and monosomic analysis of aluminum tolerance in wheat (Triticum aestivum L.). Revista Brasileira de Genética, Ribeirão Preto, 14(4):10111020, 1991.

MARTIN, J.H.; LEONARD, W.H. \& STAMP, D.L. Principles of field crop production. New York, Macmillan, $1976.1118 \mathrm{p}$.

MOORE, D.P.; KRONSTAD, W.E. \& METZGER, R.J. Screening wheat for aluminun tolerance. In: WORKSHOP ON PLANT ADAPTATION TO MINERAL STRESS IN PROBLEM SOILS. Beltsville, 1976. Proceedings. Ithaca, Cornell University, 1976. p.287-295.

WELSH, J.R. \& HEHN, E.R. The effect of chromossome 1D on hexaploid wheat flour quality. Crop Science, Madison, 4(3):320-323, 1964. 